\title{
Oral manifestations of COVID-19: Brief review
}

\author{
Anna Maria Paradowska-Stolarz ${ }^{A-F}$
}

Division of Dentofacial Anomalies, Department of Maxillofacial Orthopedics and Orthodontics, Wroclaw Medical University, Poland

A - research concept and design; $\mathrm{B}$ - collection and/or assembly of data; $\mathrm{C}$ - data analysis and interpretation;

$D$ - writing the article; $\mathrm{E}$ - critical revision of the article; $\mathrm{F}$ - final approval of the article

Address for correspondence

Anna Maria Paradowska-Stolarz

E-mail:anna.paradowska-stolarz@umed.wroc.pl

Funding sources

None declared

Conflict of interest

None declared

Received on November 4, 2020

Reviewed on November 22, 2020

Accepted on December 28, 2020

Published online on February 16, 2021

Cite as

Paradowska-Stolarz AM. Oral manifestations of COVID-19 infection: Brief review. Dent Med Probl. 2021;58(1):123-126. doi:10.17219/dmp/131989

DOI

$10.17219 / \mathrm{dmp} / 131989$

Copyright

๑ 2021 by Wroclaw Medical University

This is an article distributed under the terms of the

Creative Commons Attribution 3.0 Unported License (CC BY 3.0)

(https://creativecommons.org/licenses/by/3.0/).

\begin{abstract}
The infection with a new type of virus - severe acute respiratory syndrome coronavirus 2 (SARS-COV-2) - called coronavirus disease 2019 (COVID-19) was first described in December 2019, in Wuhan, China. Due to the gastrointestinal mucosa tropism of the virus, an attempt was made to describe the oral manifestations of the SARS-CoV-2 infection. Angiotensin-converting enzyme 2 (ACE2), which permits the attachment of the virus, is present also in the oral cavity. There are many symptoms in the oral cavity; among them, the most prevalent ones are dysgeusia (taste disorders), oral pain, the exacerbation of autoimmune diseases as well as the herpes simplex virus (HSV) and varicella zoster virus (VZV) infections. Ulcerations and aphthous stomatitis are also often mentioned. The research shows that there are many oral symptoms in COVID-19, but the coexistence with the main disease has not been fully stated and understood. There is still no clearance on whether the oral symptoms are the manifestations of the disease or occur due to the loss of the immune response. Therefore, further studies on this subject should be conducted.
\end{abstract}

Key words: COVID-19, SARS-CoV-2, oral cavity, angiotensin-converting enzyme 2 receptor 


\section{Introduction}

The novel coronavirus pneumonia was first observed in December 2019 in Wuhan, in the Hubei Province of China. World Health Organization (WHO) named the virus severe acute respiratory syndrome coronavirus 2 (SARS-CoV-2) and the disease - coronavirus disease 2019 (COVID-19). The most common symptoms are fever, cough, shortness of breath or difficulty in breathing, fatigue, and muscle or body aches. Less common features, such as headache, the loss of taste or smell, a sore throat, diarrhea, and nausea or vomiting, may be present. The severity of symptoms depends on the time of exposure to the virus, the patient's age and gender as well as the coexisting diseases. The contact and droplet modes of transmission of the virus are well known. The gastrointestinal mucosa tropism of SARS-CoV-2 has been proven by biopsies. Due to the presence of the virus in stool, gastrointestinal transmission is also possible. ${ }^{1-4}$

The COVID-19 virus binds to 2 main host cell receptors - angiotensin-converting enzyme 2 (ACE2) and transmembrane protease serine 2 (also called transmembrane serine protease or TMPRSS2). ${ }^{2}$ The severity of the coronavirus infection depends on many interactions, i.e., virus attachment, ACE2 receptor recognition, protease cleaving, and membrane fusion. The ACE2 receptor is highly expressed in the lung alveolar type 2 (AT2) cells, the esophagus, and the epithelial cells of the ileum and the colon. Apart from the above, ACE2 can also be found in the absorptive enterocytes from the ileum and the colon. ${ }^{1}$

In the oral cavity, those receptors are present mostly on the tongue and in the salivary glands. ${ }^{3}$ They also occur in the nasopharynx, oral and nasal mucosa. ${ }^{4}$ The course of infection is based on viral coagulopathy, which includes the consumption of platelets, thrombin and increased fibrin degradation products. The specific mechanism(s) of this phenomenon has not been fully understood. The treatment modalities have not been stated either. ${ }^{2}$ It is also a well-known fact that patients with autoimmune diseases are predisposed to the SARS-CoV-2 infection. ${ }^{5}$

Nostril and throat swab are the most common diagnostic tools. The molecular polymerase chain reaction (PCR) tests enable finding the SARS-CoV-2 genes. In 42.9-81.8\% of patients with a negative throat swab, the result might be positive when the probe is taken from the stool. ${ }^{6}$

The aim of this review was to briefly present the possible symptoms of COVID-19 in the oral cavity.

\section{Material and methods}

The PubMed database was searched to achieve the recent information, dating from December 2019 to October 2020. The key words were: 'COVID-19' and 'oral cavity manifestations'. Eighty-nine articles were found; among them, only 68 were full-text articles and referred to the studied topic. The chosen articles were in English only and were peer-reviewed. Twenty-one articles were written in a language other than English and were not taken into consideration. In the last step, the papers without clear background were excluded.

\section{Oral manifestations}

During the infection, SARS-CoV-2 is detected in saliva, so the salivary gland transmission of the virus is also possible. ${ }^{1}$ The oral cavity, as part of the gastrointestinal duct, is also rich in ACE2 receptors, especially in the salivary glands and the dorsum of the tongue. Most of the symptoms present in the oral cavity are due to the impaired immune system and/or susceptible oral mucosa. ${ }^{3}$

The frequency of oral manifestations of COVID-19 is not known, but a huge study of 666 patients suggests that oral cavity findings are present in $25.65 \%$ of cases. ${ }^{7,8}$ It is hypothesized that mild severity of disease is related to no symptoms or minor symptoms of the disease. ${ }^{7,8}$ The common symptoms are blisters, ulcerations and desquamative gingivitis. ${ }^{9}$ The ulcerations of the tongue occur quite often. The observations show that most of them are non-bleeding, but painful. They are always present on the dorsum or side of the tongue. Only in $15 \%$ of patients, tongue ulcerations develop on the ventral surface. ${ }^{10}$ All the ulcerations and wounds may also result from the formation of thrombi and vasculitis in the oral cavity. ${ }^{11}$ Doctors reported white plaque on the dorsum of the tongue during the SARS-CoV-2 infection as well. ${ }^{2}$ The plaque did not react to antifungal treatment. It was retrospectively recognized as geographic tongue with an exacerbation during COVID-19. Additionally, multiple pinpoint yellowish ulcers on the dorsum of the tongue were present; those were probably the late-stage ulcers of the herpetic infection. ${ }^{2}$ Herpes simplex virus (HSV) ulcerations are usually associated with stress due to presence of the disease and are not a specific symptom of the SARS-CoV-2 infection. ${ }^{12}$ Frequently, ulcerations are combined with swelling. ${ }^{13}$ Herpes zoster (HZ) disease might also be manifested. ${ }^{10}$ Other oral symptoms might be explained through the aggravation of immune/defense mechanisms toward the present lesions. The most commonly observed are pemphigus, lichen planus, pemphigoid, and Sjögren's syndrome. ${ }^{4}$ A specific set of symptoms, called Kawasaki-like symptoms, is the most severe oral manifestation. This includes erythema, dryness, the fissuring, peeling, cracking, and bleeding of mucosa and the lips, and strawberry tongue. Apart from oral manifestations, cervical lymphadenopathy is also observed. ${ }^{14}$ In the case of COVID-19, the mimic of Kawasaki syndrome is called multisystem inflammatory syndrome in children (MIS-C) or hyperinflammatory shock. It is observed mainly in children. A sore throat, malaise, diarrhea and abdominal sensations, anorexia, rash skin, and conjunctivitis are other symptoms. ${ }^{15}$ 
Fungal infections are also one of the common oral manifestations of SARS-CoV-2, probably caused by lower immunity. ${ }^{16}$ It has to be mentioned that a case of a neonate with COVID-19 and oral cavity candidiasis has been described. ${ }^{17}$

The most frequent locations of the COVID-19 symptoms are the palate and the tongue, followed by the gums and the lips. Patients report pain in $75 \%$ of cases. ${ }^{18}$ Oral lesions heal within 3-21 days, either spontaneously or through topical treatment and oral hygiene. ${ }^{19}$

Most of the lesions in the oral cavity are prior to COVID-19 infection or result from the applied treatment. ${ }^{3}$ Some patients may present with problems regarding soft tissues, saliva production and neurologically based oral sensations, even after a full recovery from COVID-19. ${ }^{4}$ It is stated that olfactory and taste disturbances are the only oral symptoms of COVID-19. Dysgeusia and the loss of scent are caused by the edema of the respiratory epithelium. ${ }^{12}$ Most of the patients (91\%) report taste changes before other symptoms occur. ${ }^{20,21}$ As many as $33.9 \%$ of patients present taste or olfactory disorders (e.g., anosmia) ${ }^{20}$ and $18.6 \%$ - both of these. ${ }^{21}$ Other researches show that $25 \%$ of patients reported impaired taste, $15 \%$ had burning sensations and 20\% difficulty in swallowing. ${ }^{22}$ Ageusia is observed in $24 \%$ of patients, hypogeusia in $35 \%$ and dysgeusia in $38 \% .{ }^{19}$ Taste disorders are more common in women than men. ${ }^{19}$ It has also been reported that instead of the loss of taste, metallic taste was felt. ${ }^{14}$

A strong correlation between oral cavity manifestations and COVID-19 has also been shown. The appearance of oral lesions depends on the severity of the main disease. During the treatment of the viral infection, oral symptoms recede as well. ${ }^{23}$

All the symptoms mentioned above are collected in Table 1.

The recent research by Emodi-Perlman et al. shows that also the temporomandibular joint and muscles are involved in COVID-19. ${ }^{24}$ The authors proved that the worldwide situation had increased the frequency of anxiety and resulted in the rise of temporomandibular disorders and bruxism. ${ }^{24}$

Table 1. Oral manifestations of severe acute respiratory syndrome coronavirus 2 (SARS-CoV-2) infection $2,3,7,8,13,14,19$

\begin{tabular}{|c|c|}
\hline $\begin{array}{c}\text { Region } \\
\text { of the oral cavity }\end{array}$ & Symptoms \\
\hline Tongue dorsum & $\begin{array}{l}\text { white plaque and erythematous plaque, yellowish } \\
\text { ulcerations (HSV), exacerbation of geographic tongue, } \\
\text { candidiasis, thrush, ulcers, transient lingual papillitis, } \\
\text { glossitis, lateral indentations, patch depapillation }\end{array}$ \\
\hline Oral mucosa & $\begin{array}{c}\text { ulcerations, petechiae, stomatitis (specifically } \\
\text { aphthous stomatitis), exacerbation of autoimmune } \\
\text { disorders, blisters, macules, mucositis }\end{array}$ \\
\hline Gingivae & gingivitis, desquamative gingivitis \\
\hline Other & $\begin{array}{l}\text { dysgeusia (taste disorders), xerostomia, oral pain, } \\
\text { erythematous surface in the oropharynx } \\
\text { and on the hard palate, oral petechiae, a sore throat, } \\
\text { Kawasaki-like disease, pruritus }\end{array}$ \\
\hline
\end{tabular}

HSV - herpes simplex virus.

\section{Conclusions}

It has neither been confirmed nor disproven that the oral cavity is a place of manifestation of the SARS-CoV-2 infection and COVID-19. We still have to remember that oral-fecal transmission is possible, especially that the virus is detected in stool months after the beginning of the infection, even after the respiratory symptoms disappear. ${ }^{25,26}$ A conclusion that oral manifestations may not be symptomatic of SARS-CoV-2, but may result from the exacerbation of other diseases, should be made. ${ }^{27}$ It also has to be remembered that the oral cavity is full of ACE2 receptors, which have a strong affinity to the COVID-19 virus.

\section{ORCID iDs}

Anna Maria Paradowska-Stolarz (D) https://orcid.org/0000-0003-2817-1445

\section{References}

1. Gu J, Han B, Wang J. COVID-19: Gastrointestinal manifestations and potential fecal-oral transmission. Gastroenterology. 2020;158(6):1518-1519. doi:10.1053/j.gastro.2020.02.054

2. Kipshidze N, Dangas $G$, White $C J$, et al. Viral coagulopathy in patients with COVID-19: Treatment and care. Clin Appl Thromb Hemost. 2020;26:1076029620936776. doi:10.1177/1076029620936776

3. Amorim dos Santos J, Costa Normando AG, Carvalho da Silva RL, et al. Oral mucosal lesions in a COVID-19 patient: New signs or secondary manifestations? Int J Infect Dis. 2020;97:326-328. doi:10.1016/j.ijid.2020.06.012

4. Dziedzic A, Wojtyczka R. The impact of coronavirus infectious disease 19 (COVID-19) on oral health. Oral Dis. 2020. doi:10.1111/ odi.13359

5. Ferri C, Giuggioli D, Raimondo V, et al.; COVID-19 \& ASD Italian Study Group. COVID-19 and rheumatic autoimmune systemic diseases: Report of a large Italian patients series. Clin Rheumatol. 2020;39(11):3195-3204. doi:10.1007/s10067-020-05334-7

6. Cha MH, Regueiro M, Sandhu DS. Gastrointestinal and hepatic manifestations of COVID-19: A comprehensive review. World J Gastroenterol. 2020;26(19):2323-2332. doi:10.3748/wjg.v26.i19.2323

7. Vieira AR. Oral manifestations in coronavirus disease 2019 (COVID-19). Oral Dis. 2020. doi:10.1111/odi.13463

8. Nuno-Gonzalez A, Martin-Carrillo P, Magaletsky K, et al. Prevalence of mucocutaneous manifestations in 666 patients with COVID-19 in a field hospital in Spain: Oral and palmoplantar findings. $\mathrm{Br} J \mathrm{Der}$ matol. 2021;184(1):184-185. doi:10.1111/bjd.19564

9. Sinadinos A, Shelswell J. Oral ulceration and blistering in patients with COVID-19. Evid Based Dent. 2020;21(2):49. doi:10.1038/s41432020-0100-z

10. Riad A, Kassem I, Hockova B, Badrah M, Klugar M. Tongue ulcers associated with SARS-CoV-2 infection: A case series. Oral Dis. 2020. doi:10.1111/odi.13635

11. Cruz Tapia RO, Peraza Labrador AJ, Guimaraes DM, Matos Valdez LH. Oral mucosal lesions in patients with SARS-CoV-2 infection. Report of four cases. Are they a true sign of COVID-19 disease? Spec Care Dentist. 2020. doi:10.1111/scd.12520

12. Al-Khatib A. Oral manifestations in COVID-19 patients. Oral Dis. 2020. doi:10.1111/odi.13477

13. Kitakawa D, Oliveira FE, Neves de Castro P, Carvalho LFCS. Short report - herpes simplex lesion in the lip semimucosa in a COVID-19 patient. Eur Rev Med Pharmacol Sci. 2020;24(17):9151-9153. doi:10.26355/eurrev_202009_22863

14. Capocasale G, Nocini R, Faccioni $P$, et al. How to deal with coronavirus disease 2019: A comprehensive narrative review about oral involvement of the disease. Clin Exp Dent Res. 2020. doi:10.1002/cre2.332

15. Al Ameer HH, AlKadhem SM, Busaleh F, AlKhwaitm S, Llaguno MBB. Multisystem inflammatory syndrome in children temporally related to COVID-19: A case report from Saudi Arabia. Cureus. 2020;12(9):e10589. doi:10.7759/cureus.10589 
16. Riad A, Gad A, Hockova B, Klugar M. Oral candidiasis in non-severe COVID-19 patients: Call for antibiotic stewardship. Oral Surg. 2020. doi:10.1111/ors.12561

17. Dima M, Enatescu I, Craina M, Petre I, lacob ER, lacob D. First neonates with severe acute respiratory syndrome coronavirus 2 infection in Romania: Three case reports. Medicine (Baltimore). 2020;99(33):e21284. doi:10.1097/MD.0000000000021284

18. Garcia de Sousa FAC, Paradella TC. Considerations on oral manifestations of COVID-19. J Med Virol. 2021;93(2):667-668. doi:10.1002/jmv.26451

19. Amorim Dos Santos J, Normando AGC, Carvalho da Silva RL, et al. Oral manifestations in patients with COVID-19: A living systematic review. J Dent Res. 2021;100(2):141-154. doi:10.1177/0022034520957289

20. Odeh ND, Babkair H, Abu-Hammad S, Borzangy S, Abu-Hammad A, Abu-Hammad O. COVID-19: Present and future challenges for dental practice. Int J Environ Res Public Health. 2020;17(9):3151. doi:10.3390/ijerph17093151

21. Giacomelli A, Pezzati L, Conti F, et al. Self-reported olfactory and taste disorders in patients with severe acute respiratory coronavirus 2 infection: A cross-sectional study. Clin Infect Dis. 2020;71(15):889-890. doi:10.1093/cid/ciaa330

22. Sinjari B, D'Ardes $D$, Santilli $M$, et al. SARS-CoV-2 and oral manifestation: An observational, human study. J Clin Med. 2020;9(10):3218. doi:10.3390/jcm9103218

23. Brandão TB, Gueiros LA, Melo TS, et al. Oral lesions in patients with SARS-CoV-2 infection: Could the oral cavity be a target organ? Oral Surg Oral Med Oral Pathol Oral Radiol. 2021;131(2):e45-e51. doi:10.1016/j.0ooo.2020.07.014

24. Emodi-Perlman A, Eli I, Smardz J, et al. Temporomandibular disorders and bruxism outbreak as a possible factor of orofacial pain worsening during the COVID-19 pandemic - concomitant research in two countries. J Clin Med. 2020;9(10):3250. doi:10.3390/jcm9103250

25. Su S, Shen J, Zhu L, et al. Involvement of digestive system in COVID-19: Manifestations, pathology, management and challenges. Therap Adv Gastroenterol. 2020;13:1756284820934626. doi:10.1177/1756284820934626

26. Cheung KS, Hung IFN, Chan PPY, et al. Gastrointestinal manifestations of SARS-CoV-2 infection and virus load in fecal samples from a Hong Kong cohort: Systematic review and meta-analysis. Gastroenterology. 2020;159(1):81-95. doi:10.1053/j.gastro.2020.03.065

27. Ponce $J B$, Tjioe KC. Overlapping findings or oral manifestations in new SARS-CoV-2 infection. Oral Dis. 2020. doi:10.1111/odi.13478 